\title{
DEMPLOT PENANAMAN SEMANGGI DENGAN FORMULA ORGANIK CAIR DI LAHAN KERING
}

\author{
Adi Budiwan ${ }^{1}$, Dwiyana Anela Kursniasari ${ }^{2}$, Heri Susanto ${ }^{3}$ \\ Universitas Wijaya Putra
}

adibudiwan@uwp.ac.id,dwiyanaanela@uwp.ac.id, herisusanto@uwp.ac.id

\begin{abstract}
Abstrak
Kampung Semanggi RW 3 Kendung Sememi Surabaya, sepanjang tahunnya menanam semanggi. Saat terjadi kemarau yang panjang besar kemunkinan terjadi kematian, dengan adanya perlakuan penyimaran menggunakan formula organik cair diharapkan mampu untuk menambah masa tanam bahkan bisa tumbuh lebih baik dan menghasilkan hasil yang maksimal. Demplot lahan semanggi sebagai bukti yang akan memberikan solusi dalam budidaya semanggi yang optimal dan ramah lingkungan. Metode kegiatan yang dilakukan dalam demplot ini meliputi ceramah tentang : bagaimana budidaya semangi di lahan kering, bagaimana mmemberikan pupuk yang tepat untuk semanggi melalui penerapan formula organik cair, bagaimana cara pembuatan pestida nabati dan bagaimanan penggunaan pestisida nabati. Persiapan Pelaksanaan, Tempat demplot budidaya semangi di lahan kering hanya sepetak lahan yang tersedia dengan sarana yang lengkap. Alat-alat yang digunakan hanya yang diperluka saja agar dalam proses demplot tidak kerepotan. Hasil panen semanggi secara fisik cukup memuaskan dalam artian daun cukup lebar (kualitas), dan otomatis akan menambah volume berat dalam bobotnya (kuantitas).
\end{abstract}

Kata Kunci : Demplot; Semanggi; FOC; Pestisida nabati

\section{PENDAHULUAN}

PPM ini bermitra dengan petani semanggi di Kampung Semanggi RW 3 Kendung Sememi Surabaya, dengan jarak tempuh dari kampus Universitas Wijaya Putra sekitar $\pm 3,3 \mathrm{~km}$. usaha yang dikembangkan oleh mitra tersebut adalah usaha semanggi.

Semanggi merupakan tanaman sepanjang tahun. Saat kemarau yang panjang, dipastikan akan menghadapi kematian, dengan perlakuan penyimaran manggunakan formula organik cair diharapkan untuk tumbuh lebih baik bahkan menghasilkan hasil yang sangat tinggi.
Mitra yang mempunyai sepetak tanah yang terletak di Kendung Sememi Surabaya yang merupakan lahan rawa (berair) yang ditanami semanggi. Mitra meruakan petani semanggi ang terbentuk berdasarkan kesamaan profesi yaitu sebagai pembudidaya semanggi. Perwakilan mitta merupakan bapak kepala rumah tangga yang berprofesi sebagai petani, dan masyarakat lain yang tertarik mengembangkan petanian semanggi. Alasan mereka adalah hasil semanggi cukup menjajikan dan mempunyai prospek yang cukup bagus. Oleh karena itu kami merekayasa budidaya semanggi di lahan kering. Karena pada saat musim kemarau, 
mitra mengeluh banyak tanaman mereka banyak yang mati.

Permasalahan yang dihadapi oleh mitra usaha adalah tanaman semanggi saat musim kemarau tidak tahan terhadap kekeringan. Solusi yang kami tawarkan adalah dengan perlakuan penyiraman formula organik cair secara intensif sehingga semanggi tumbuh lebih baik dan menghasilkan hasil yang bagus. Selain mengandung hara yang komplit, pupuk organik bersifat higroskopis, bisa meyimpan air di saat musim kemarau, yang diharapkan membantu pertumbuhan semanggi pada saat musim kemarau.

PPM ini berusaha untuk memecahkan permasalahan yang dihadapi mitra usaha dengan perlakuan seperti di atas dan perberian pestisida nabati secara berkala, sehingga menghasilkan tanaman semanggi yang ramah lingkungan.

\section{METODE}

Pelaksanaan meliputi survai untuk mengetahui sejauh kualitas dan kuantitas, pengumpulan data berkaitan dengan luas lahan, jumlah petani, jumlah panen, kualitas hasil panen, dan metode pelaksanaan yang dilakukan, solusi melalui pembuatan pestisida nabati dan demplot, manbandingkan hasil dengan menghitung nilai tambah. Metode yang digunakan dalam pelaksanaan kegiatan Program Pemberdayaan Masyarakat ini adalah sebagai berikut:

1. Penyuluhan dan pelatihan budidaya semanggi di lahan kering untuk petani semanggi, yaitu dengan melakukan diskusi dan pengarahan sebelum memualai demplot.

2. Pelatihan pembelajaran untuk petani semanggi. Dalam hal ini menawarkan pembuatan pestida organik yang efektif dan efisien. Setelah itu, petani langsung diajak praktik sehingga dapat mengatahui cara pembuatan pestida organik tersebut.

3. Pelaksanaan demplot dengan petani. Tujuan inti dalam kegiatan ini adalah memberikan pelatihan dan pengarahan (pembuktian secara langsung kepada petani akan hasil penanaman semanggi bisa dilakkukan di saat musim kemarau dengan tiak mengurangi hasil atau bahkan ada peningkatan dari hasil panen sebelumnya.

Langkah-langkah yang dilasanakan dalam kegiatan Program Pemberdayaan Masyarakat ini adalah sebagai berikut :

1. Langkah Persiapan

a. Langkah persiapan yang dilakukan adalah mengadakan survai dan penjajagan sejauh kualitas dan kuantitas.

b. Melakukan pengumpulan data berkaitan dengan luas lahan, jumlah petani, jumlah panen, kualitas hasil panen, dan metode pelaksanaan yang telah dilakukan.

c. Melakukan kajian untuk menawarkan alternatif solusi melalui pembuatan pestisida organic dan demplot semanggi lahan kering.

2. Langkah Pelaksanaan

a. Pelaksanaan pelatihan, tentang: (1) pembuatan pestisida organik; (2) metode pembuatan demplot yang efektif dan efisien, (3) pemberian formula organic cair dan pestisida organik, dan (4) manbandingkan hasil dengan menghitung nilai tambah.

b. Tahap evaluasi

Dilakukan melalui tiga tahap, yakni evaluasi persiapan, evaluasi proses, dan evaluasi hasil.

c. Tahap pelaporan

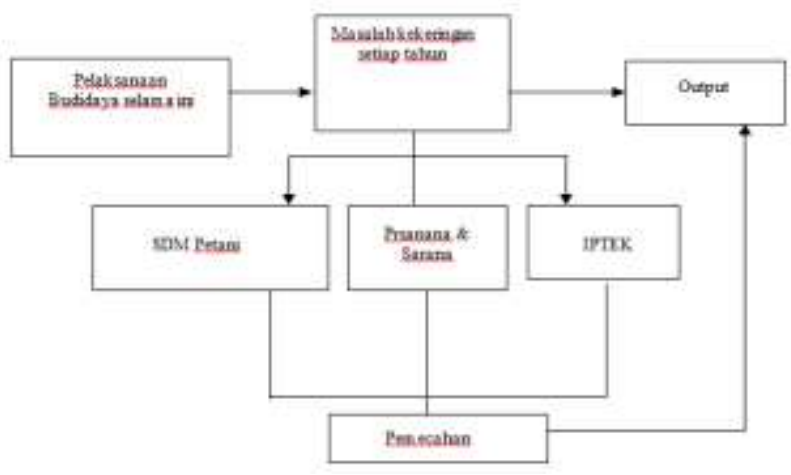

Gambar 1 Kerangka Pemecahan Masalah 


\section{HASIL DAN PEMBAHASAN}

Hasil yang telah dicapai pada program pengabdian masyarakat ini antara lain:

1. Persiapan

Persiapan program pengabdian masyarakat ini diawali dengan survei lokasi dan koordinasi dengan Ketua RT Kampung Semanggi RW 3 Kendung Sememi. Kemudian dilanjutkan dengan menemui warga Kampung Semanggi. Kegiatan koordinasi ini dilakukan guna memberitahukan kepada mitra bahwa proposal yang diajukan telah disetujui untuk mendapatkan dana dari Univesitas Wijaya Putra. Selain itu, kegiatan ini juga dimaksudkan untuk memperoleh ijin dari Ketua RT untuk memanfaatkan lahan berada di wilayah setempat untuk diguankan sebagai lahan demplot dengan menggunakan teknologi pupuk B40 dan pompa air. Sementara, kegiatan survei lokasi dimaksudkan untuk menganalisis kondisi lahan demplot dan penempatan pompa yang dibutuhkan saat penyiraman.

2. Diskusi dan Pengumpulan Referensi

Pada tahap ini tim mengumpulkan referensi tentang model yang digunakan untuk demplot, diskusi tentang jalur pipanisasi dan lokasi pompa. Tim juga melakukan perencanaan bahan yang akan dibeli, disesuaikan dengan jumlah anggaran yang disetujui, yaitu Rp 6.000.000.

3. Perencanaan Demplot dan Lokasi Penempatan Pompa

Demplot yang dititik lokasi yang berdekatan penempatan pompa. Luas demplot sekitar 6 meter. Dari pumpa air dialirkan menuju lahan demplot. Pemilihan titik lokasi demplot dilakukan berdasarkan diskusi bersama Ketua RT Kampung Semanggi RW 3 Kendung Sememi dan warga Kampung Semanggi. Adapun titik lokasi yang dipilih adalah sebagai berikut.

Pestisida nabati adalah pestisida yang bahan aktifnya berasal dari tumbuhan atau bagian tumbuhan seperti akar, daun, batang atau buah (Rahardjo, 2010). Beberapa tanaman mengandung bahan-bahan kimia yang dapat membunuh, menarik, atau menolak serangga. Beberapa tumbuhan menghasilkan racun, mengandung senyawasenyawa kompleks yang dapat mengganggu siklus pertumbuhan serangga, sistem pencernaan, atau mengubah perilaku serangga.

Pestisida Nabati Daun Sirsak Dan Tembakau

- Pestisida nabati daun sirsak dan tembakau efektif untuk mengendalikan hama belalang dan ulat.

- Cara pembuatan: sebanyak 50 lembar daun sirsak dan tembakau satu genggam ditumbuk halus. Bahanbahan tersebut dimasukkan ke dalam larutan 20 liter air dan 20 gram detergen (sabun solek), diaduk rata, dan direndam selama semalam, kemudian disaring. Tiap 1 liter larutan hasil penyaringan diencerkan dengan 50-60 liter air.

- Larutan pengenceran siap digunakan.

4. Formula Organik Cair

Pupuk merupakan bahan yang ditambahkan ke dalam tanah untuk menyediakan unsur hara yang penting bagi pertumbuhan tanaman. Penggolongan pupuk umumnya didasarkan pada sumber bahan yang digunakan, cara aplikasi, bentuk dan kandungan unsur haranya. (Hadisuwito, 2012)

Formula Organik Cair merupakan hasil atau perubahan atau peruraian bagianbagian batu-batuan, misalnya dolomit, zeolit, guano, tepung fosil serta limbahlimbah organik yang lain yang telah dikelola dan dapat memasok unsur hara yang dibutuhkan oleh tanaman.

Pupuk organik mempunyai karakteristik kandungan hara rendah, ketersediaan unsur hara lambat, dan menyediakan hara dalam jumlah terbatas dan hara rendah.Ada beberapa manfaat pupuk yang berkaitan dengan sifat kimia tanah. Manfaat pupuk yang paling banyak dirasakan penggunaannnya adalah : menyediakan 
unsur hara yang diperlukan bagian tanaman, membantu mencegah kehilangan unsur hara yang cepat hilang seperti nitrogen, fosfor dan kalium., memperbaiki keasaman tanah (Marsono, 2001).

5. Praktek Budidaya Tanaman Semanggi.

Semanggi bertumbuh sangat baik di dalam sawah, rawa-rawa dangkal. Cukup masukkan bibit semanggi ke lahan lalu siram Formula Organik Cair ke lahan tersebut. Setelah itu, tidak perlu memberi perhatian, karena Semanggi bisa mengurus diri sendiri.

Semanggi dapat beradaptasi dengan kedalaman air yang cukup, sedangkan kualitas air dengan penambahan Formula Organik Cair akan berpengaruh terhadap petumbuhan. Semanggi dapat di tanam dengan lahan kering, semanggi akan dengan sendirinya menyesuaikan diri dengan kondisi tanah dengan perlakuan hingga daun-daunnya mengembang dengan subur.

Penggunaan Formula Organik Cair di siramkan 2 (dua) hari sekali dengan takaran 25 (duapuluh lima) ml (FOC) dicampurkan dengan 5 (lima) 1 air, kemudian disemprotkan secara merata.

Pengguanaan pestisida nabati di siramkan 1 (satu) minggu sekali dengan takaran 1 (satu) 1 pestisida nabati dilarutkan dengan 50 (limapuluh) 1 air, kemudian diseprotkan secara merata. Tujuan digunakan pestisida nabati untuk pengendalian hama, terutama hama balalang dan ulat. Melihat daerah sekitar masih banyak rawa yang ditumbuhi tumbuhan liar (gulma) sehingga dijadikan sarang bagi haha-hama tersebut.

Setelah perawatan dilakukan dengan baik, maka tinggal melakukan pemanenan semanggi. Pemanenan semanggi dilakukan 2 (dua) minggu sekali dengan cara memotong semanggi sampai hampir batang bawah. Selanjutnya dilakukan perawatan seperti semula dengan pemberian Formula Organik Cair dan pestisida nabati secara tepat.
Hasil panen semanggi secara fisik dilihat dari daunnya cukup memuaskan dalam artian daun cukup lebar (kualitas), dan otomatis akan menambah volume berat dalam bobotnya (kuantitas).

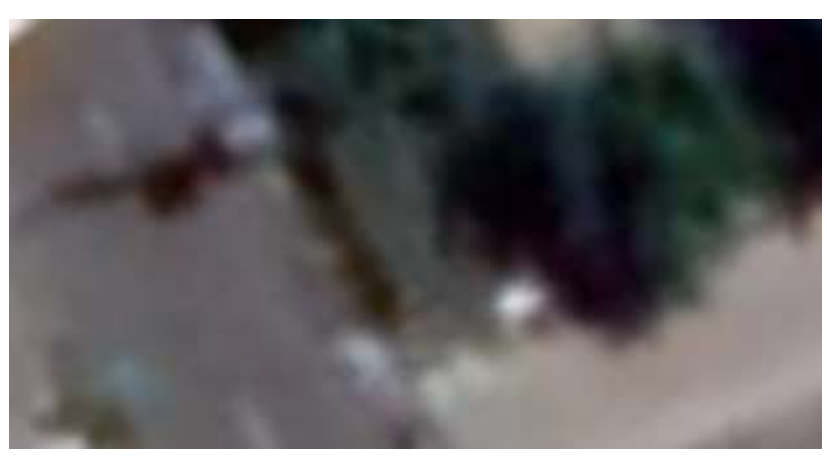

\section{Gambar 4.1. Lokasi Demplot}

\section{Persiapan Lokasi Demplot}

Lokasi yang dipilih tentunya dibersihkan terlebih dahulu. Hal ini dilakukan agar lahan demplot dapat dipastikan siap untuk ditanami semanggi.

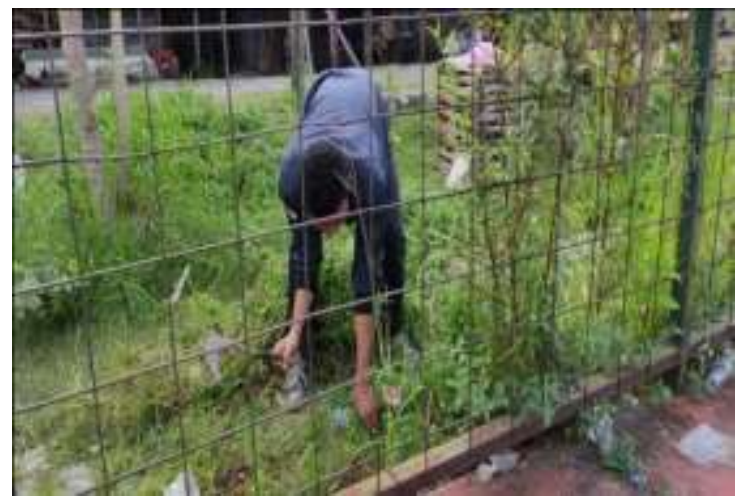

Ganbar 4.2. Pembabatan Lokasi Demplot 


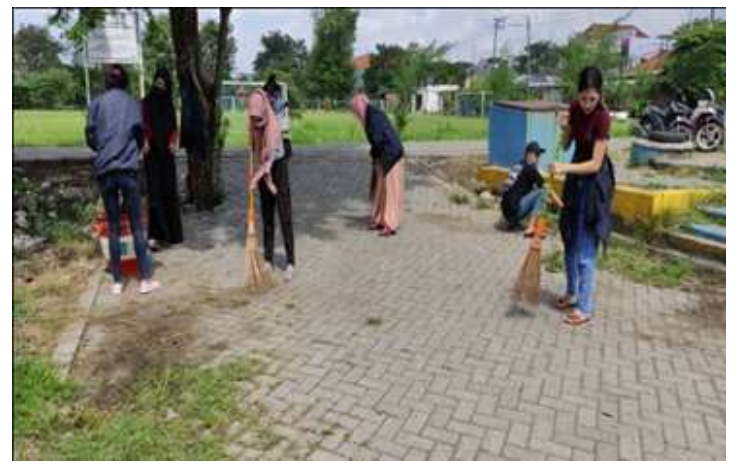

Gambar 4.3. Bangunan Pondasi Tandon

2. Pemilihan bibit semanggi

Setelah lokasi dan sekitarnya selesai dibersikan dan siap untuk diolah untuk ditanami semanggi, perlu untuk memilih bibit semanggi yang bagus.

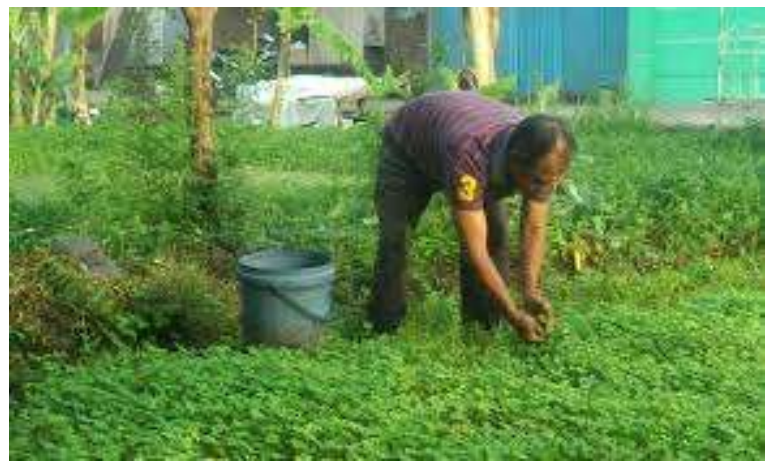

Gambar 4.4. Pemilihan Bibit Semanggi

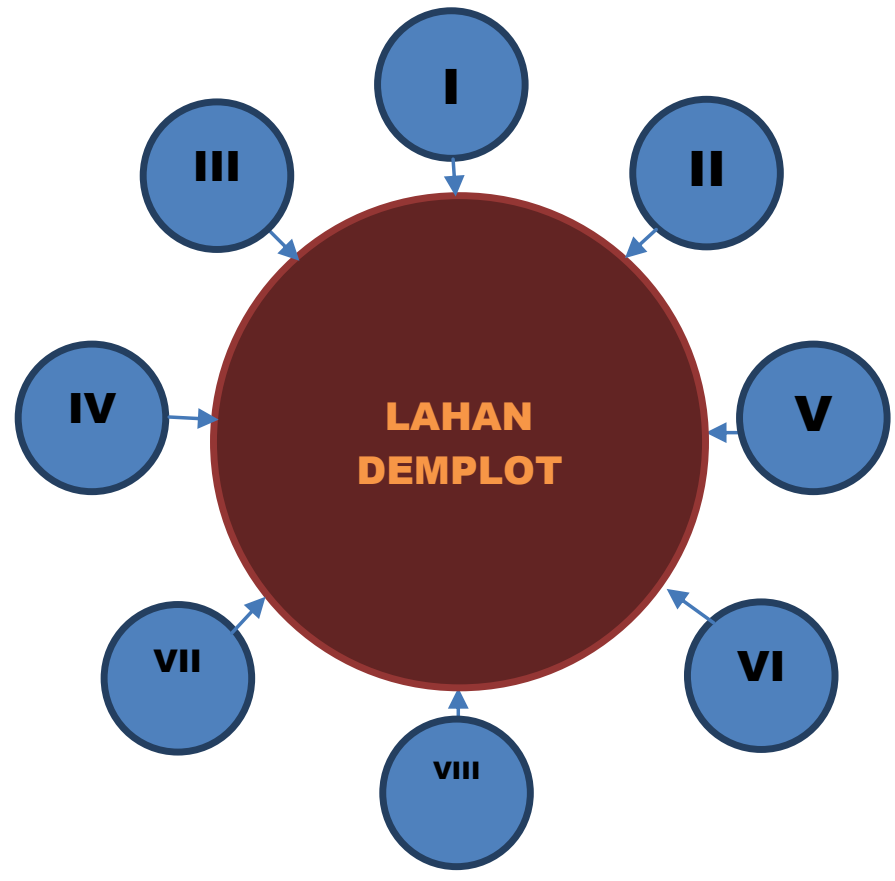

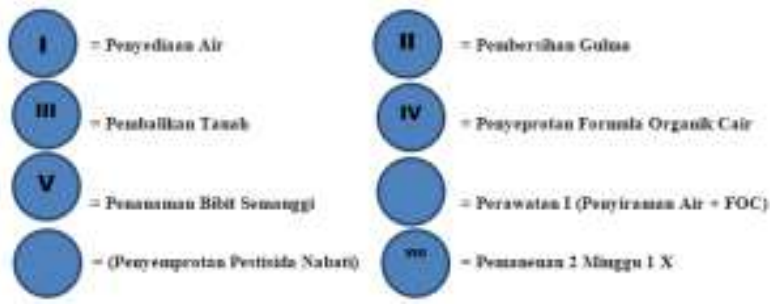

\section{KESIMPULAN}

Dari hasil pembahasan diatas dapat ditarik suatu kesimpulan bahwa :

1. Budidaya semanggi dapat lasanakan di lahan kering dengan perlakuan penyiraman secara intensif, sehingga memambah masa tanam di lahan kering.

2. Pernyiraman Formula Organik Cair yang intensif dan penggunaan pestisida nabati yang tepat, akan meningkat secara kualitas dan kuantitas..

\section{UCAPAN TERIMAKASIH (Bila ada)}

Ucapan terima kasih kami yang ditujukan pada Universitas Wijaya Putra lembaga yang memberikan bantuan selama program ini berlangsung

Ucapan terima kasih kami disampaikan kepada Petani Kampung Semanggi RW 3 Kendung Sememi Surabaya.

\section{REFERENSI}

Firda Kurniawati. 2019. Semanggi Suroboyo Desa Kendung Benowo-Surabaya Sebagai Sumber Belajar Berbasis Etnopedagogi Di Sekolah Dasar. JPGSD. Volume 07 Nomor 03 Tahun 2019, 3061 3070

Hadisuwito, sukamto. 2012. "Membuat Pupuk Cair”. PT. Ago Media Pustaka. Jakarta.

Hery Widijanto, Suntoro. 2019. Pembuatan Demplot Budidaya Tanaman Jagung Dalam Menambah Masa Tanam Di Lahan Kering Dengan Memanfaatkan Pupuk organik, PRIMA: Journal of Community Empowering and Services 
Prosiding PKM-CSR, Vol. 4 (2021)

e-ISSN : 2655-3570

28-32 e-

ISSN: 2579-5074

Soenandar, M; M. N. Aeni; A. Rahardjo., 2010.

Marsono, P. S. 2001. Pupuk Akar, Jenis dan

Aplikasi. Penebar Swadaya. Jakarta

Petunjuk Praktik Membuat Pestisida Organik. Agromedia Pustaka. Jakarta. 